\title{
Comparison of Alpha 200 and CoughAssist as Intermittent Positive Pressure Breathing Devices: A Bench Study
}

\author{
Gaël Bourdin MD, Claude Guérin MD PhD, Véronique Leray MD, Bertrand Delannoy MD, \\ Sophie Debord MD, Frédérique Bayle MD, Michèle Germain MD, \\ and Jean-Christophe Richard MD PhD
}

\begin{abstract}
BACKGROUND: Intermittent positive pressure breathing (IPPB) is used in non-intubated patients to increase lung volume and to enhance coughing. Alpha 200 (Salvia Lifetec, Kronberg, Germany) is a specific IPPB device. CoughAssist (Respironics France, Carquefou, France) is a mechanical insufflator-exsufflator used to remove secretions in patients with inefficient cough. Both can also be used for intubated or tracheotomized patients. We assessed the impact of various artificial airways on the ability of the Alpha 200 and CoughAssist to generate insufflated volume. METHODS: We measured the insufflated volume and pressure at the airway opening in a lung model under 2 conditions of compliance ( 30 or $60 \mathrm{~mL} / \mathrm{cm} \mathrm{H}_{2} \mathrm{O}$ ) at single resistance of $5 \mathrm{~cm} \mathrm{H}_{2} \mathrm{O} / \mathrm{L} / \mathrm{s}$. The devices were used at 2 set pressures: 30 and $40 \mathrm{~cm} \mathrm{H} \mathrm{H}_{2} \mathrm{O}$. The Alpha 200 was set at 2 inflation flows: 0.5 and $1 \mathrm{~L} / \mathrm{s}$, whereas CoughAssist was set at its highest value of $10 \mathrm{~L} / \mathrm{s}$. Measurements were done without (control) and with different size endotracheal tubes and tracheostomy cannulae. The relationships between insufflated volume and measured pressure were analyzed using linear regressions. RESULTS: The slopes and intercepts of the control relationship between insufflated volume and pressure were significantly greater with Alpha 200 at each set flow than with CoughAssist. As artificial airways were used, the insufflated volume did not differ from the control with CoughAssist, while with Alpha 200 it increased at each flow setting and for all mechanical conditions. The largest differences in insufflated volume between the 2 devices were observed for the largest endotracheal tubes and tracheostomy cannulas and for the lowest inflation flow setting in Alpha 200. These results can be explained in terms of how the devices function, as CoughAssist adapts by increasing flow, while Alpha 200 adapts by increasing inspiratory time. CONCLUSIONS: This bench study has shown that in the presence of artificial airways the value of the insufflated volume generated by the CoughAssist device was significantly lower than that generated by the Alpha 200 device. Key words: insufflation-exsufflation; intermittent positive pressure breathing; IPPB; cough; tracheostomy; airway; endotracheal tube. [Respir Care 2012;57(7):1129-1136. (C 2012 Daedalus Enterprises]
\end{abstract}

\section{Introduction}

Intermittent positive pressure breathing (IPPB) is the delivery of a slow deep sustained inspiration by means of a mechanical device in spontaneously breathing patients.

\footnotetext{
The authors are affiliated with the Service de Réanimation Médicale et d'Assistance Respiratoire, Hôpital de la Croix Rousse, and with the University of Lyon, Lyon, France; with the exception of Dr Germain, who is affiliated with the Laboratoire d'Explorations Fonctionnelles Respiratoires, Hôpital de la Croix-Rousse and University of Lyon, Lyon, France.
}

The authors have disclosed no conflicts of interest.
IPPB is indicated to prevent or treat atelectasis that is unresponsive to other therapies, and to help clear secretions. It has been claimed that IPPB is an effective alter-

\footnotetext{
Supplementary material related to this paper is available at http:// www.rcjournal.com.

Correspondence: Claude Guérin MD PhD, Service de Réanimation Médicale et d'Assistance Respiratoire, Hôpital de la Croix Rousse, 103 Grande Rue de la Croix Rousse, 69004 Lyon, France. E-mail: claude.guerin@ chulyon.fr.
}

DOI: $10.4187 /$ respcare. 01344 
native to tracheostomy in patients with neuromuscular disease. ${ }^{1,2}$ ICU patients often suffer from severe neuromuscular weakness, which may arise from either chronic neuromuscular disease or critical illness neuromyopathy. ${ }^{3-6}$ Critical illness neuromyopathy may prolong the duration of mechanical ventilation. ${ }^{7,8}$ Furthermore, the optimal strategy for weaning these patients off ventilators has not been formally established. One option could be to keep the patient intubated as long as their respiratory muscle performance and cough ability are suboptimal. Another alternative is tracheostomy. Finally, the strategy could consist of extubation followed by intensive noninvasive mechanical ventilation and mechanical cough assist. This strategy has been shown to be efficient and safe in patients with chronic neuromuscular disease intubated for acute respiratory failure. ${ }^{9}$ IPPB may have a role to play in the weaning strategy for intubated ICU patients with critical illness neuromyopathy. IPPB can be applied while the patient is still intubated or tracheotomized and breathing spontaneously, or after extubation as an adjunct to noninvasive mechanical ventilation.

Different IPPB devices are available, in France the most commonly used is the Alpha 200 (Salvia Lifetec, Kronberg, Germany). CoughAssist (Respironics France, Carquefou, France) is a mechanical insufflator-exsufflator device that can be also used as an IPPB device. For both devices, an endotracheal tube (ETT) or tracheostomy cannula is an obstacle to optimal performance, as the narrower the internal diameter of the ETT or tracheostomy cannula, the greater the increase in flow resistance, and hence the lower the volume entering the lung during the inspiration from the device ${ }^{1}$ for a given inspiratory pressure. Since there are no data on the impact of ETT or tracheostomy cannula on each device's ability to maintain insufflated volume delivery, we carried out a bench study to investigate the effect of ETT and tracheostomy cannula of various sizes on both devices' effectiveness in generating insufflated volume. Part of this study, focusing on CoughAssist's performance in generating peak expiratory flow, has been already reported. ${ }^{10}$ Our working hypothesis in the present study was that the device's performance is impaired by artificial airway and that the extent of this impairment depends on the size of the ETT or tracheostomy cannula.

\section{Methods}

\section{Equipment}

The setup used comprised the following items: brand new CoughAssist and Alpha 200 devices, fully checked by the manufacturer prior to the present investigation; a 2-lung configuration test lung (Training and Test Lung, Michigan Instruments, Grand Rapids, Michigan) with ad-

\section{QUICK LOOK}

\section{Current knowledge}

Mechanical insufflation-exsufflation has been demonstrated to assist in providing lung expansion and secretion clearance in selected patient populations. The presence of an artificial airway reduces the peak expiratory flow and inspired volumes achieved by different insufflation-exsufflation devices.

\section{What this paper contributes to our knowledge}

In this bench study the presence of an artificial airway reduced the inspired tidal volume and peak expiratory flow generated by 2 insufflation-exsufflation devices. The inspired tidal volume generated by the CoughAssist device was significantly lower than that generated by the Alpha 200 device.

justable compliance and parabolic resistors that mimic airway resistance; a data acquisition system containing a pneumotachograph (Fleisch 4, Fleisch, Lausanne, Switzerland) for air flow measurement; a straight connector (VBM Medizintechnik, Sulz, Germany) to measure pressure at the airway opening $\left(\mathrm{P}_{\mathrm{ao}}\right)$; brand new ETTs (Hi-Lo, Mallinckrodt Medical, Athlone, Ireland) of various internal diameters $(6.5,7.0,7.5,8.0,8.5 \mathrm{~mm}$ ID); and tracheostomy cannulae (Mallinckrodt Medical, Athlone, Ireland) (6.0, 7.0, $8.0 \mathrm{~mm}$ ID). The pneumotachograph was linear over a -10 to $+10 \mathrm{~L} / \mathrm{s}$ flow range. The flow and $\mathrm{P}_{\text {ao }}$ ports were connected to piezoresistive transducers (BD Gabarith, Vogt Medical, Karlsruhe, Germany). The signals were amplified, sent to analog-digital hardware (MP150, Biopac Systems, Goleta, California), and recorded at $200 \mathrm{~Hz}$ (Acqknowledge, Biopac Systems, Goleta, California).

\section{Protocol}

The experiment was conducted over one day in our hospital's pulmonary function test laboratory at room temperature and in room air. The piezoresistive transducers were calibrated before the measurements were taken, using a rotameter flow meter (Martin Médical, Lyon, France) for flow, and a manometer (Companion, Puritan Bennett, Indianapolis, Indiana) for $\mathrm{P}_{\mathrm{ao}}$.

Two values of compliance, 30 and $60 \mathrm{~mL} / \mathrm{cm} \mathrm{H}_{2} \mathrm{O}$, each at a fixed resistance of $5 \mathrm{~cm} \mathrm{H}_{2} \mathrm{O} / \mathrm{L} / \mathrm{s}$, were applied in a random order to each ETT or tracheostomy cannula. The rationale to select values of resistance and compliance was based upon the following reasoning. A search in the literature for resistance and compliance measured in patients with neuromuscular disease intubated in the ICU was un- 

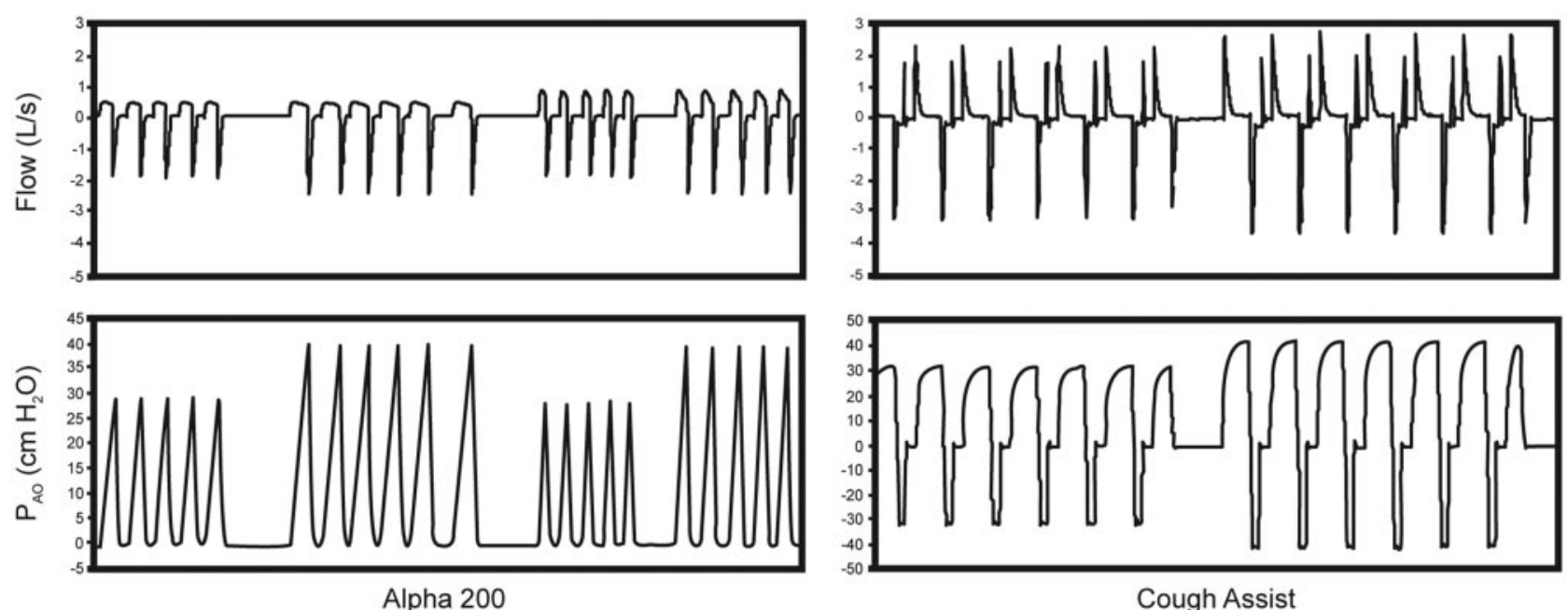

Fig. 1. Records of flow and pressure $\left(P_{\text {ao }}\right)$ over time in Alpha 200 and CoughAssist under the control (absence of artificial airway) in the compliance of $30 \mathrm{~mL} / \mathrm{cm} \mathrm{H}_{2} \mathrm{O}$ and resistance of $5 \mathrm{~cm} \mathrm{H}_{2} \mathrm{O} / \mathrm{L} / \mathrm{s}$ (C30R5) mechanical condition. Alpha 200 was used at the 2 possible flows, while CoughAssist was set at its highest inspiratory flow.

successful. Therefore we used data from patients with kyphoscoliosis who also had a restrictive lung disorder and in whom respiratory mechanics were measured in the ICU. In these patients, resistance and lung compliance averaged $6.2 \mathrm{~cm} \mathrm{H}_{2} \mathrm{O} / \mathrm{L} / \mathrm{s}$ and $67 \mathrm{~mL} / \mathrm{cm} \mathrm{H}_{2} \mathrm{O}$, respectively. ${ }^{11} \mathrm{We}$ also chose the compliance value of $30 \mathrm{~mL} / \mathrm{cm} \mathrm{H}_{2} \mathrm{O}$ (C30) to mimic a condition with very low lung compliance. For each mechanical condition a control condition was recorded, in which the pneumotachograph and $\mathrm{P}_{\mathrm{a}}$ port were directly attached to the test lung, and no ETT or tracheostomy cannula or resistor R5 was inserted.

For both devices, insufflation was triggered automatically. Regarding the CoughAssist, inspiratory flow was set at a single value, which was its highest value $(10 \mathrm{~L} / \mathrm{s})$. This was done in order to achieve the set pressure with the narrower artificial airways. ${ }^{10}$ Regarding Alpha 200, the inspiratory flow was used at 2 preset values: flow 1 was $0.5 \mathrm{~L} / \mathrm{s}$ and flow 2 was $1 \mathrm{~L} / \mathrm{s}$ (Fig. 1). The CoughAssist device was set to an inspiratory/expiratory time of 3/1 second, with a 1 second pause between expiration and inspiration. Expiratory resistance was set to off in the Alpha 200 device. For both devices, we set similar inspiratory pressures of $30 \mathrm{~cm} \mathrm{H}_{2} \mathrm{O}$ (P30) and $40 \mathrm{~cm} \mathrm{H}_{2} \mathrm{O}$ (P40), and applied them successively, in this order, for each condition. A negative pressure was also set with CoughAssist (see Fig. 1), but not retained for the purpose of the study.

At least 5 insufflations were performed for each data set (see Fig. 1). Once recording was stable, the last 5 respiratory cycles were retained for the analysis (see Fig. 1). The insufflated volume was obtained from the numerical integration of the flow signal.

\section{Data Analysis}

The experiment generated 108 combinations ( 2 mechanical conditions $x 9$ reference and artificial airways x 2 set pressures $x 3$ set inspiratory flows) of 5 repetitions each making a total of 540 measurements.

The main outcome measure was insufflated volume. We measured the real $\mathrm{P}_{\mathrm{ao}}$ and used a linear regression analysis to model the relationship of insufflated volume to $\mathrm{P}_{\mathrm{a}}$ and quantify the interaction with the device and the artificial airways. The maximal inspiratory $\mathrm{P}_{\mathrm{ao}}$ was centered on $36 \mathrm{~cm} \mathrm{H}_{2} \mathrm{O}$, which was the average value across all the measurements. Thereby, insufflated volume was fitted to maximal inspiratory $\mathrm{P}_{\mathrm{ao}}-36$, so the intercept is the value of insufflated volume at $36 \mathrm{~cm} \mathrm{H}_{2} \mathrm{O}$ maximal $\mathrm{P}_{\mathrm{ao}}$.

Four models were tested, 2 pertaining to the resistance and compliance conditions, and, for each of them, to each inspiratory flow used (ie, CoughAssist versus Alpha 200 flow 1 and CoughAssist versus Alpha 200 flow 2 each at C30R5 and C60R5). Each mechanical condition was analyzed separately because we aimed at testing the effects of the device and the artificial airways in different mechanical conditions, which were understood as representing different respiratory mechanics occurring in ICU patients.

Each model was provided with the estimates of 2 parameters, the intercept and the slope, with their standard error values. A reduction in the slope between the devices means a lower increase in insufflated volume for the same change in $\mathrm{P}_{\mathrm{ao}}$ for a given artificial airway.

The slopes were compared between the devices as the deviation of the slope of a device from the other taken as 
the reference. A 3-step strategy was followed in the analysis. The first step assessed the effect of the device without artificial airways in the control condition. The second step assessed the effect of the presence or absence of the artificial airways, irrespective of its size, according to the device. The third step assessed the effect of the size of artificial airways for each device. The analysis used the treatment contrasts and was provided with intercept, slope, difference between 2 intercepts, and difference between 2 slopes.

Additional secondary end points were mean inspiratory flow and inspiratory time. Two series of comparisons were made: of the 2 nominal levels of set pressure between CoughAssist and Alpha 200 at each flow setting, and of the 2 levels of set inspiratory flow with Alpha 200. Comparisons were made across the artificial airways under each mechanical condition, using paired $t$ tests with a Dunn-Bonferroni correction to address the issue of multiple comparisons.

The estimates of the slopes and intercepts were expressed as mean \pm standard error. The values of inspiratory flow and time were expressed as mean $\pm \mathrm{SD}$. The correlation coefficient was used in the regression analysis. The statistical analysis was carried out using statistics software ( $\mathrm{R}$, version 2.9.0, R Foundation for Statistical Computing, Vienna, Austria). $P<.05$ was set as the threshold for statistical significance.

\section{Results}

\section{Control Condition With No Artificial Airways}

For both mechanical conditions, the values of slopes and intercepts were statistically significantly reduced with CoughAssist, as compared to Alpha 200, in the control condition (ie, with no artificial airway) (see the supplementary materials at http://www.rcjournal.com).

\section{Effect of Artificial Airways}

The model was first improved by adding the effect of the presence (or absence) of artificial airways, irrespective of their size. The estimates of the coefficients of the linear regression and the effects of the device and the presence/ absence of artificial airways are given in the tables in the supplementary materials (at http://www.rcjournal.com) for the C30R5 and C60R5 mechanical conditions, respectively. Relative to the Alpha 200 device, with no artificial airway taken as the reference, at each flow, the presence of an artificial airway significantly increased the intercept for both mechanical conditions. It also significantly increased the slope in the case of flow 2 for each mechanical condition. The presence of artificial airways significantly decreased the intercepts with CoughAssist at each flow for both mechanical conditions. It significantly decreased the slope with CoughAssist only in the condition C60R5 in the case of flow 2.

The model was further enhanced by taking into account the size of the artificial airways. The relationships between the insufflated volume and $\mathrm{P}_{\text {ao }}$ for every artificial airway and device are shown in the figures in the supplementary materials for C30R5 and C60R5 mechanical conditions, respectively. These relationships were linear in all instances (correlation coefficient $>0.99$ ). The effects on the values of the coefficients of the model of artificial airways and device are shown in the supplementary materials for Alpha 200 at flow 1, with no artificial airway taken as the reference, in the C30R5 condition. Each artificial airway was associated with a significant increase in both intercept and slope with Alpha 200, except for intercept with ETT 6.5. The greater the internal diameter of the ETT, the greater the increase in volume. This increase was much greater than the internal diameter of the ETT was larger. By contrast, each artificial airway was associated with a significant decrease in both intercept and slope with CoughAssist, except for ETT 6.5. This decrease tended to be much greater than the internal diameter of the ETT was larger. Similar results were obtained for Alpha 200 flow 1 in the C30R5 condition and for the C60R5 condition (not shown).

The values of slopes and intercepts were computed for all devices under all mechanical conditions and for all artificial airways (Table). They were significantly lower with CoughAssist than with Alpha 200 for all the artificial airways (see Table).

\section{Discussion}

The present bench study found that insufflated volume delivery from the CoughAssist device is reduced by ETT or tracheostomy cannula, as compared to Alpha 200.

\section{Effects of IPPB on Lung Volume}

IPPB has primarily been used to increase lung volumes in neuromuscular non-intubated patients. ${ }^{12}$ However, it should be stressed that the physiological effects of IPPB have been poorly investigated. An increase in lung volume elicited by IPPB has been found in some studies of patients with neuromuscular impairment. ${ }^{13-15}$ However, other investigators found that lung volume did not change after application of $20-40 \mathrm{~cm} \mathrm{H}_{2} \mathrm{O}$ IPPB in 10 patients with generalized muscle weakness. ${ }^{16}$ The way IPPB is administered may, however, influence the results. In unselected non-intubated patients the inspiratory capacity during coached IPPB significantly increased by almost half a liter, compared to an unassisted inspiratory maneuver. ${ }^{17}$ In the same investigation, coached IPPB with ventilatory set- 
Table. Values of Intercepts and Slopes Computed From the Estimates of the Coefficients of the Linear Regression Analysis Between Inspired Volume and Maximal Inspiratory Pressure in Each Mechanical Condition, for Each Device and Each Artificial Airway

\begin{tabular}{|c|c|c|c|c|c|c|c|c|c|c|c|c|}
\hline \multirow{4}{*}{$\begin{array}{l}\text { Artificial } \\
\text { Airway }\end{array}$} & \multicolumn{12}{|c|}{ Compliance $30 \mathrm{~mL} / \mathrm{cm} \mathrm{H}_{2} \mathrm{O}$, Resistance $5 \mathrm{~cm} \mathrm{H}_{2} \mathrm{O} / \mathrm{L} / \mathrm{s}$} \\
\hline & \multicolumn{4}{|c|}{ Alpha 200 Flow 1} & \multicolumn{4}{|c|}{ Alpha 200 Flow 2} & \multicolumn{4}{|c|}{ Cough Assist } \\
\hline & \multicolumn{2}{|c|}{ Intercept, L } & \multicolumn{2}{|c|}{ Slope, $\mathrm{L} / \mathrm{cm} \mathrm{H}_{2} \mathrm{O}$} & \multicolumn{2}{|c|}{ Intercept, L } & \multicolumn{2}{|c|}{ Slope, $\mathrm{L} / \mathrm{cm} \mathrm{H}_{2} \mathrm{O}$} & \multicolumn{2}{|c|}{ Intercept, L } & \multicolumn{2}{|c|}{ Slope, $\mathrm{L} / \mathrm{cm} \mathrm{H}_{2} \mathrm{O}$} \\
\hline & Mean & SE & Mean & SE & Mean & SE & Mean & SE & Mean & SE & Mean & SE \\
\hline Control & 1.280 & 0.001 & 0.039 & 0.0001 & 1.130 & 0.002 & 0.036 & 0.0001 & 1.093 & 0.001 & 0.030 & 0.002 \\
\hline ETT 6.5 & 1.180 & 0.005 & 0.038 & 0.001 & 1.020 & 0.001 & 0.042 & 0.0001 & $1.004 *$ & 0.002 & $0.027 *$ & 0.005 \\
\hline ETT 7 & 1.360 & 0.003 & 0.044 & 0.001 & 1.100 & 0.003 & 0.044 & 0.001 & $1.048^{*}$ & 0.001 & $0.033^{*}$ & 0.003 \\
\hline ETT 7.5 & 1.440 & 0.001 & 0.045 & 0.000 & 1.140 & 0.002 & 0.042 & 0.0001 & $1.058 *$ & 0.001 & $0.030 *$ & 0.002 \\
\hline ETT 8.0 & 1.650 & 0.002 & 0.052 & 0.003 & 1.220 & 0.004 & 0.050 & 0.001 & $1.030 *$ & 0.001 & $0.022 *$ & 0.0001 \\
\hline ETT 8.5 & 1.720 & 0.003 & 0.053 & 0.001 & 1.260 & 0.005 & 0.046 & 0.001 & $1.060^{*}$ & 0.002 & $0.030^{*}$ & 0.004 \\
\hline Trach 6.0 & 1.720 & 0.002 & 0.057 & 0.0001 & 1.180 & 0.003 & 0.050 & 0.001 & $0.990 *$ & 0.001 & $0.028^{*}$ & 0.003 \\
\hline Trach 7.0 & 1.770 & 0.004 & 0.055 & 0.001 & 1.270 & 0.004 & 0.049 & 0.001 & $1.010^{*}$ & 0.001 & $0.029^{*}$ & 0.004 \\
\hline \multirow[t]{2}{*}{ Trach 8.0} & 1.830 & 0.003 & 0.055 & 0.0001 & 1.320 & 0.004 & 0.047 & 0.001 & $1.033 *$ & 0.001 & $0.029 *$ & 0.004 \\
\hline & \multicolumn{12}{|c|}{ Compliance $60 \mathrm{~mL} / \mathrm{cm} \mathrm{H}_{2} \mathrm{O}$, Resistance $5 \mathrm{~cm} \mathrm{H}_{2} \mathrm{O} / \mathrm{L} / \mathrm{s}$} \\
\hline Control & 2.600 & 0.003 & 0.078 & 0.001 & 2.300 & 0.004 & 0.070 & 0.001 & 2.093 & 0.002 & $0.063^{*}$ & 0.004 \\
\hline ETT 6.5 & 2.490 & 0.002 & 0.080 & 0.0001 & 2.060 & 0.0001 & 0.090 & 0.004 & $1.950 *$ & 0.001 & $0.048^{*}$ & 0.003 \\
\hline ETT 7 & 2.690 & 0.002 & 0.088 & 0.001 & 2.180 & 0.003 & 0.090 & 0.001 & $2.020 *$ & 0.002 & $0.055^{*}$ & 0.004 \\
\hline ETT 7.5 & 3.010 & 0.004 & 0.097 & 0.001 & 2.340 & 0.004 & 0.090 & 0.001 & $2.060 *$ & 0.003 & $0.051^{*}$ & 0.006 \\
\hline ETT 8.0 & 3.300 & 0.002 & 0.106 & 0.0001 & 2.410 & 0.007 & 0.100 & 0.001 & $2.080 *$ & 0.001 & $0.060 *$ & 0.003 \\
\hline ETT 8.5 & 3.520 & 0.006 & 0.112 & 0.001 & 2.560 & 0.006 & 0.090 & 0.001 & $2.080 *$ & 0.002 & $0.057 *$ & 0.007 \\
\hline Trach 6.0 & 3.450 & 0.002 & 0.114 & 0.0001 & 2.350 & 0.002 & 0.111 & 0.0001 & $1.950 *$ & 0.001 & $0.051^{*}$ & 0.003 \\
\hline Trach 7.0 & 3.580 & 0.003 & 0.114 & 0.001 & 2.530 & 0.003 & 0.100 & 0.001 & $2.020 *$ & 0.001 & $0.055^{*}$ & 0.003 \\
\hline Trach 8.0 & 3.680 & 0.002 & 0.117 & 0.001 & 2.630 & 0.003 & 0.097 & 0.001 & $2.060 *$ & 0.002 & $0.058^{*}$ & 0.004 \\
\hline
\end{tabular}

tings adjustments resulting in pressures ranging between 20 and $50 \mathrm{~cm} \mathrm{H}_{2} \mathrm{O}\left(30 \mathrm{~cm} \mathrm{H}_{2} \mathrm{O}\right.$ on average) increased inspiratory capacity by almost one liter, compared to the unassisted maneuver. ${ }^{17}$ However, the increase in lung volume was not associated with an increase in respiratorysystem compliance in 14 non-intubated neuromuscular patients treated for 20 min with $20-25 \mathrm{~cm} \mathrm{H}_{2} \mathrm{O}$ IPPB, ${ }^{13}$ as it was in 14 patients with high spinal cord injury after 2 months of IPPB. ${ }^{18}$ This finding may suggest that IPPB has displaced the pressure-volume curve of the respiratory system toward its upper flat part, and, hence may reflect IPPB-induced lung hyperinflation.

\section{Indication of IPPB}

It has recently been concluded that IPPB may be useful in increasing tidal volume and enhancing cough effectiveness in patients with neuromuscular disease or spinal cord injuries. ${ }^{19}$ With an IPPB device the peak expiratory flow can increase as a result of greater lung inflation. The CoughAssist device can be used to increase cough effectiveness. ${ }^{20}$ However, the effect of the CoughAssist device on peak expiratory flow depends on its ability to promote lung inflation. CoughAssist may be helpful in the management of neuromuscular patients by facilitating weaning from invasive mechanical ventilation in ICUs. ${ }^{9}$ Therefore, both devices may have a role in the management of weaning ICU patients with neuromuscular weakness off invasive mechanical ventilation. Therefore, we decided to compare them and to focus the comparison on the insufflated volume delivery for the following reasons. First, there are a limited number of IPPB devices available, and CoughAssist can be used for this purpose. Second, as we have recently shown, artificial airways significantly reduce peak expiratory flow generated by CoughAssist. ${ }^{10}$ We therefore wondered whether this may result, at least in part, from a reduction in insufflated volume due to the artificial airway. Finally, to our knowledge, this is the first systematic in vitro comparison of the performance of both devices.

\section{Effects of Artificial Airways on Insufflated Volume}

It is well known that artificial airways increase airway resistance. ${ }^{21,22}$ As a result, greater pressure is required to 

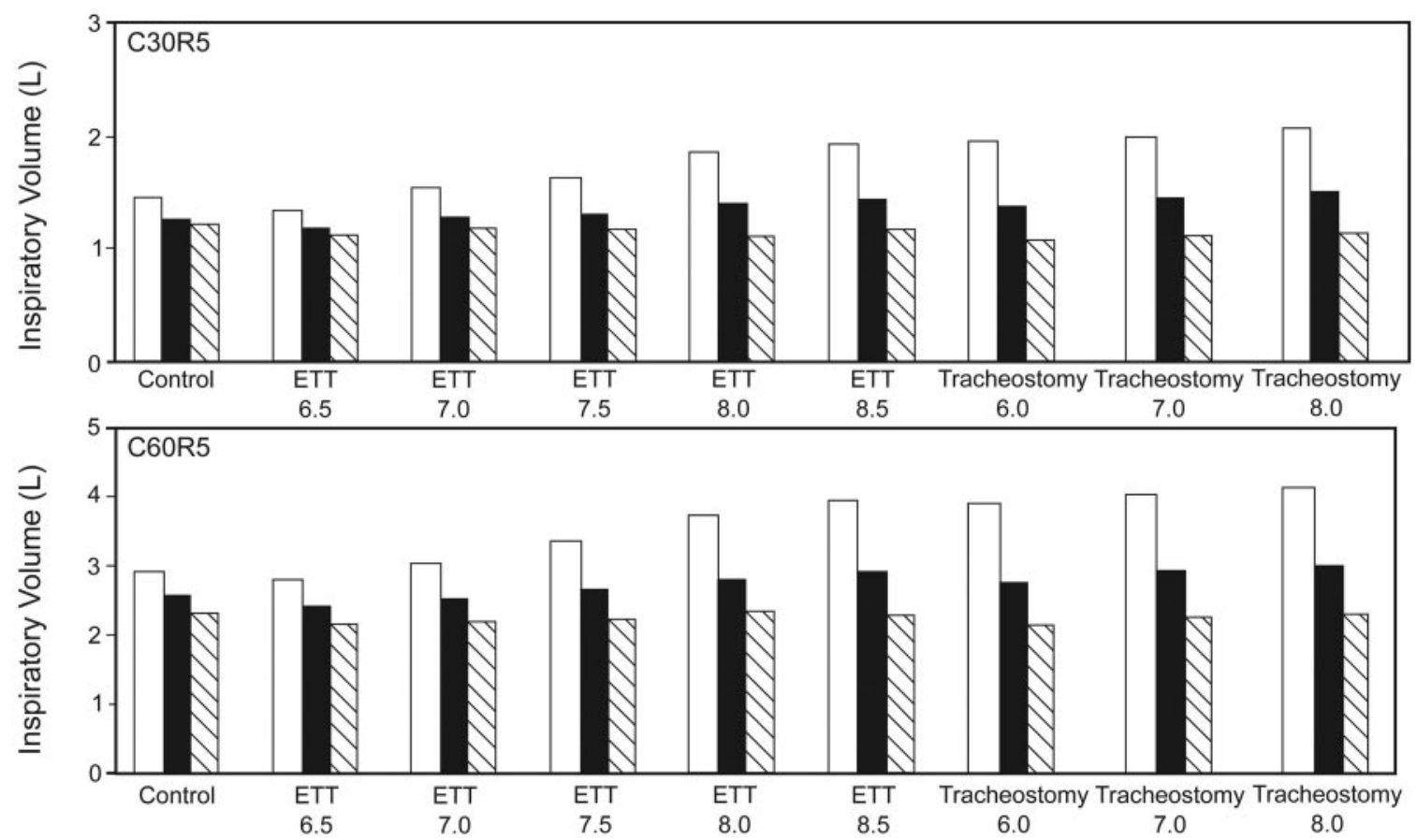

Fig. 2. Mean values of computed inflation volume for a pressure of $40 \mathrm{~cm} \mathrm{H} \mathrm{H}_{2} \mathrm{O}$ from Alpha 200 at low (black bars) and high (white bars) flows and from CoughAssist (hatched bars) for compliance of $30 \mathrm{~mL} / \mathrm{cm} \mathrm{H}_{2} \mathrm{O}$ and resistance of $5 \mathrm{~cm} \mathrm{H} \mathrm{H}_{2} \mathrm{O} / \mathrm{L} / \mathrm{s}$ (C30R5) and compliance of $60 \mathrm{~mL} / \mathrm{cm} \mathrm{H}_{2} \mathrm{O}$ and resistance of $5 \mathrm{~cm} \mathrm{H} \mathrm{O} / \mathrm{L} / \mathrm{s}$ (C60R5) mechanical conditions across control condition and the presence of artificial airways (size range 6.5-8 $\mathrm{mm}$ ). ETT = endotracheal tube.

generate a given air flow and hence a given insufflated volume. Since the insufflated volume is the integral of air flow over inspiratory time, maintaining the insufflated volume when pressure increases requires a rise in either flow or inspiratory time. We analyzed how each device adapts when set $P_{a o}$ increases (see Fig. 1). To raise $P_{a o}$, the Alpha 200 device increases inspiratory time while the mean inspiratory flow does not change, at each inspiratory flow setting. Furthermore, the inspiratory flow profile changes from a constant to a decelerating shape as $\mathrm{P}_{\mathrm{ao}}$ increases (see Fig. 1). The CoughAssist device works in the opposite manner, as it increases inspiratory flow in order to raise $\mathrm{P}_{\mathrm{ao}}$, while inspiratory time does not change (see Fig. 1). The values for inspiratory time in Alpha 200 and for mean inspiratory flow in CoughAssist were significantly greater at P40 than P30 under both mechanical conditions (not shown). For the Alpha 200 device under the C30R5 condition, at the lower and higher inspiratory flow settings, respectively, mean \pm SD inspiratory flow was $0.47 \pm 0.03 \mathrm{~L} / \mathrm{s}$ versus $0.77 \pm 0.06 \mathrm{~L} / \mathrm{s}(P<.001)$ and inspiratory time was $3.21 \pm 0.66 \mathrm{~s}$ versus $1.46 \pm 0.37 \mathrm{~s}$ $(P<.001)$ across all artificial airways. These values amounted to $0.48 \pm 0.03 \mathrm{~L} / \mathrm{s}$ versus $0.83 \pm 0.07 \mathrm{~L} / \mathrm{s}$ $(P<.001)$ and $6.35 \pm 1.31 \mathrm{~s}$ versus $2.69 \pm 0.76 \mathrm{~s}(P<.001)$ for the C60R5.

Each device tested uses different strategies, as Alpha 200 increases inspiratory time while CoughAssist delivers greater inspiratory flow. This was expected because, by definition, the inspiratory time was fixed at $3 \mathrm{~s}$ and was actually maintained by the machine at this level throughout the experiment. The strategy, which consists of increasing inspiratory time, seems more effective than that of increasing inflation flow to maintain the insufflated volume, as the artificial airway is present whichever the mechanical load. Therefore, the performance of the Alpha 200 device in maintaining the insufflated volume was better than that for CoughAssist with an increasing resistive load.

The effect of set inflation flow in Alpha 200 on insufflated volume delivery was a secondary end point of the study. We observed that this factor influenced the device's performance. We found that the values of slopes and intercepts were systematically higher with the lower inflation flow (flow 1) than with the higher value (flow 2) for all the mechanical conditions and artificial airways tested (see Table). This resulted from the combined effect of 2 factors, which were independent of both the lung mechanical condition and the respiratory load. First, for any set pressure, inspiratory time was roughly 2 times lower with the lower, as compared to the higher, inflation flow setting. Second, the concomitant inflation flow was less than 2 times higher for the higher, as compared to the lower, inflation flow setting. 


\section{Clinical Implications}

The insufflated volume values resulting from a set pressure of $40 \mathrm{~cm} \mathrm{H}_{2} \mathrm{O}$ were computed using the parameters of the linear regressions (see Table) of the present experiment and are presented in Figure 2. With CoughAssist the insufflated volume values remained essentially the same across the artificial airways for each mechanical condition. However, with Alpha 200 the insufflated volume values increased, compared to the control, as soon as an artificial airway was present, under each mechanical condition. Therefore, the insufflated volume values were higher with Alpha 200 than with CoughAssist. The difference in insufflated volume between the 2 devices was even greater for the lower set inspiratory flow with Alpha 200. The largest differences between the 2 set inspiratory flows with Alpha 200, on the one hand, and between the 2 devices, on the other, were observed for all tracheostomy cannulae and for the largest ETT. The differences were much smaller, but were probably still clinically important, for the narrowest ETTs.

This has clear implications in terms of both device selection and settings selection for IPPB. First, the Alpha 200 device appears superior to CoughAssist in delivering insufflated volume in the presence of an artificial airway, regardless of how the lung's mechanical properties are altered. Second, the highest insufflated volume is obtained when using Alpha 200 at its lowest inflation flow. On the other hand, the insufflated volume delivered using the CoughAssist device was stable across the various artificial airways, which can be considered a strength of the device. Third, the differences in insufflated volume between the 2 devices were clinically relevant. For the target pressure of $40 \mathrm{~cm} \mathrm{H}_{2} \mathrm{O}$, with ETT 8.5 or tracheostomy cannula 8.0, a relative difference of $>40 \%$ was obtained, representing $>1 \mathrm{~L}$. According to the American Association for Respiratory Care Clinical Practice Guideline, ${ }^{12}$ an insufflated volume of about $1.2 \mathrm{~L}$ is recommended for lung expansion therapy (in a $70 \mathrm{~kg}$ adult patient). This target was reached with Alpha 200 in the presence of each artificial airway, but was virtually never reached with CoughAssist in the present experimental conditions.

It should be kept in mind that the use of Alpha 200 may increase the risk of lung hyperinflation, especially when low inflation flow is used. This is the result of both high insufflated volume and long inspiratory time. The impairment of peak expiratory flow in CoughAssist in the presence of an artificial airway previously observed in the bench study ${ }^{10}$ can be partly explained by a limitation in insufflated volume generation.

\section{Study Limitations}

The main limitation of the study is that it is an in vitro study. The results cannot be extrapolated to the in vivo condition. One of the reasons for this is that we used a single-compartment model. In this case, the respiratory system mechanical inequalities were not considered. These inequalities directly influence the volume-pressure relationship during pulmonary inflation, as in an inhomogeneous system the lung accommodates higher volumes with lower inspiratory flows and longer inspiratory times. Therefore, the present results should be further investigated in vivo.

\section{Conclusions}

In conclusion, this bench study has shown that in the presence of an artificial airway the insufflated volume generated by the CoughAssist device was significantly lower than that generated by the Alpha 200 device.

\section{REFERENCES}

1. Gujanica Z, Jankovic I, Jevtic D, Markovic M, Marjanovic B, Jankovic B. [Results of intensive therapy of meningococcal sepsis in children]. Srp Arh Celok Lek 2001;129(Suppl 1):42-46. Article in Serbian.

2. Bach JR, Alba AS, Saporito LR. Intermittent positive pressure ventilation via the mouth as an alternative to tracheostomy for 257 ventilator users. Chest 1993;103(1):174-182.

3. Bolton CF. Neuromuscular manifestations of critical illness. Muscle Nerve 2005;32(2):140-163.

4. Johnson KL. Neuromuscular complications in the intensive care unit: critical illness polyneuromyopathy. AACN Adv Crit Care 2007;18(2): 167-180.

5. Lacomis D. Critical illness myopathy. Curr Rheumatol Rep 2002; 4(5):403-408.

6. Schweickert WD, Hall J. ICU-acquired weakness. Chest 2007;131(5): 1541-1549.

7. De Jonghe B, Bastuji-Garin S, Sharshar T, Outin H, Brochard L. Does ICU-acquired paresis lengthen weaning from mechanical ventilation? Intensive Care Med 2004;30(6):1117-1121.

8. De Jonghe B, Sharshar T, Lefaucheur JP, Authier FJ, DurandZaleski I, Boussarsar M, et al. Paresis acquired in the intensive care unit: a prospective multicenter study. JAMA 2002;288(22): 2859-2867.

9. Bach JR, Goncalves MR, Hamdani I, Winck JC. Extubation of patients with neuromuscular weakness: a new management paradigm. Chest 2010;137(5):1033-1039.

10. Guérin C, Bourdin G, Leray V, Delannoy B, Bayle F, Germain M, Richard JC. Performance of the CoughAssist insufflation-exsufflation device in presence of endotracheal tube or tracheotomy tube: a bench study. Respir Care 2011;56(8)1108-1114.

11. Conti G, Rocco M, Antonelli M, Bufi M, Tarquini S, Lappa A, et al. Respiratory system mechanics in the early phase of acute respiratory failure due to severe kyphoscoliosis. Intensive Care Med 1997;23(5): 539-544.

12. Sorenson HM, Shelledy DC. AARC Clinical Practice Guideline. Intermittent positive pressure breathing: 2003 revision and update. Respir Care 2003;48(5):540-546.

13. McCool FD, Mayewski RF, Shayne DS, Gibson CJ, Griggs RC, Hyde RW. Intermittent positive pressure breathing in patients with respiratory muscle weakness: alterations in total respiratory system compliance. Am Rev Respir Dis 1986;90(4):546-552. 


\section{Comparison of Alpha 200 and CoughAssist as IPPB Devices}

14. Guerin C, Vincent B, Petitjean T, Lecam P, Luizet C, Rabilloud M, et al. The short-term effects of intermittent positive pressure breathing treatments on ventilation in patients with neuromuscular disease. Respir Care 2010;55(7):866-872.

15. Stiller K, Simionato R, Rice K, Hall B. The effect of intermittent positive pressure breathing on lung volumes in acute quadriparesis. Paraplegia 1992;30(2):121-126.

16. De Troyer A, Deisser P. The effects of intermittent positive pressure breathing on patients with respiratory muscle weakness. Am Rev Respir Dis 1981;124(2):132-137.

17. Welch MA Jr, Shapiro BJ, Mercurio P, Wagner W, Hirayama G. Methods of intermittent positive pressure breathing. Chest 1980; 78(3):463-467.

18. Laffont I, Bensmail D, Lortat-Jacob S, Falaize L, Hutin C, Le Bomin
E, et al. Intermittent positive-pressure breathing effects in patients with high spinal cord injury. Arch Phys Med Rehabil 2008;89(8): 1575-1579.

19. Denehy L, Berney S. The use of positive pressure devices by physiotherapists. Eur Respir J 2001;17(4):821-829.

20. Chatwin M, Ross E, Hart N, Nickol AH, Polkey MI, Simonds AK. Cough augmentation with mechanical insufflation/exsufflation in patients with neuromuscular weakness. Eur Respir J 2003;21(3): 502-508.

21. Nunn JF. Applied respiratory physiology. London: Butterworths; 1987.

22. Gal TJ, Suratt PM. Resistance to breathing in healthy subjects following endotracheal intubation under topical anesthesia. Anesth Analg 1980;59(4):270-274. 